\title{
Uncommon bilateral maxillary exostosis: case report
}

\author{
Exostose maxilar bilateral incomum: relato de caso
}

\author{
Ana Luiza Lataliza COSTA ${ }^{1}$ iD https://orcid.org/0000-0002-0683-9275 \\ Ana Luísa Machado BATISTA1 iD https://orcid.org/0000-0002-3259-1971 \\ Sara Ferreira dos Santos COSTA1 ID https://orcid.org/0000-0001-5150-9227 \\ Juliana Vilela BASTOS ${ }^{2}$ iD https://orcid.org/0000-0002-2062-2566 \\ Roselaine Moreira Coelho MILAGRES1 ${ }^{1}$ https://orcid.org/0000-0002-9490-1912 \\ Tânia Mara Pimenta AMARAL1 iD https://orcid.org/0000-0001-8254-0497
}

\begin{abstract}
Exostoses or hyperostoses are benign bony outgrowths originating from the cortical bone and depend on their location for a more precise designation. The most common types found in the oral cavity are the torus palatinus and the torus mandibularis. Buccal and palatal exostoses are located along the buccal aspect of the maxilla and/or the mandible (commonly in the premolar and molar areas) and on the palatal aspect of the maxilla (usually in the tuberosity area), respectively. The etiology of exostoses still hasn't been enlightened but an interaction between environmental and genetic factors is accredited. They are usually asymptomatic, unless the mucosa becomes ulcerated. The frequency of exostoses increases with age, having their biggest prevalence from 60 years old, being more common in men and suffering ethnic influences. A thorough evaluation is important for the correct diagnosis since other lesions have similar clinical characteristics to the exostoses such as osteomas. The majority of exostoses are diagnosed clinically along with radiographic interpretations, making the biopsy dispensable and the treatment is usually unnecessary. The aim of this article was to describe a case report of bilateral maxillary exostosis, unusual, in a female patient. If an excessive amount of bone is present the exostoses may exhibit a relative radiopacity on dental radiographs. Initially, periapical and panoramic radiographs were performed to evaluate the alterations. Due to the size of the exostoses a concomitant Cone Beam Computed Tomography was performed to confirm the diagnosis. The patient is in follow-up.
\end{abstract}

Indexing terms: Exostoses. Hyperostosis. Cone-beam computed tomography.

\section{RESUMO}

Exostoses ou hiperostoses são crescimentos ósseos benignos originados da cortical óssea e dependem de sua localização para uma denominação mais precisa. Os tipos mais comuns encontrados na cavidade oral são o Tórus Palatino e o Tórus Mandibular. Exostoses bucais e palatais acometem a face vestibular do processo alveolar na maxila elou na mandibula (comumente na região de molares e pré-molares) e a superfície do processo alveolar posterior (usualmente na área da tuberosidade maxilar), respectivamente. A etiologia

\footnotetext{
$\boldsymbol{\nabla v v}$
}

1 Universidade Federal de Minas Gerais, Faculdade de Odontologia, Departamento de Clínica, Patologia e Cirurgia Odontológicas. Av. Presidente Antônio Carlos, 6627, Campus Universitário Pampulha, 31270-901, Belo Horizonte, MG, Brasil. Correspondence to: TMP Amaral. E-mail: <taniapamaral@gmail.com>

2 Universidade Federal de Minas Gerais, Faculdade de Odontologia, Departamento de Odontologia Restauradora. Belo Horizonte, MG, Brasil.

$\boldsymbol{\nabla v}$

How to cite this article

Costa ALL, Batista ALM, Costa SFS, Bastos JV, Milagres RMC, Amaral TMP. Uncommon bilateral maxillary exostosis: case report. RGO, Rev Gaúch Odontol. 2020;68:e20200024. http://dx.doi.org/10.1590/1981-863720200002420180026 
das exostoses ainda não foi esclarecida, mas acredita-se em uma interação entre fatores ambientais e genéticos. São usualmente assintomáticas, a não ser que a mucosa se torne ulcerada. A frequência aumenta com a idade, tendo sua maior prevalência a partir de 60 anos de idade, sendo mais comuns em homens e sofrendo influências étnicas. É importante uma avaliação minuciosa para o correto diagnóstico, visto que outras lesões, como os osteomas, possuem características clínicas semelhantes às das exostoses. A maior parte das exostoses é diagnosticada clinicamente em conjunto com interpretações radiográficas, tornando a biópsia dispensável e o tratamento é usualmente desnecessário. O objetivo deste artigo foi relatar um caso clínico de exostose maxilar bilateral, incomum, em uma paciente do sexo feminino. Se uma quantidade excessiva de osso está presente, as exostoses podem mostrar uma relativa radiopacidade nas radiografias dentárias. Inicialmente foram realizadas radiografias periapicais e radiografia panorâmica para avaliar as alterações. Devido ao tamanho das exostoses, realizou-se uma Tomografia Computadorizada de Feixe Cônico, para confirmação do diagnóstico. A paciente encontra-se em acompanhamento.

Termos de indexação: Exostose. Hiperostose. Tomografia computadorizada de feixe cônico.

\section{INTRODUCTION}

Exostoses or hyperostoses are benign bony outgrowths originating from the cortical bone and are classified according to their location [1]. The most common types found in the oral cavity are the torus palatinus (TP) and the torus mandibularis (TM) [1,2]. TP is a sessile and nodular bone mass located in the midline of the hard palate. TMs are bony protrusions located on the lingual side of the mandible, commonly bilateral and found in the canine and premolar areas [2]. Buccal and palatal exostoses are bony nodules that occur less frequently than torus. While buccal exostoses affect the vestibular side of the alveolar process in the maxilla and/or the mandible, usually in the molar and premolar region, palatal exostoses are found on the surface of the posterior alveolar process, usually in the area of the maxillary tuberosity [2,3].

Although the etiology of torus and exostoses is poorly understood, studies suggest that genetic [4] and environmental factors [5], masticatory hyperfunction [4,5], and continued growth [2] might play a role. A multifactorial interaction between the environmental and the genetic factors is believed to be a cause for these conditions $[5,6]$. The genetic threshold theory states that the environmental factors must first reach a threshold level before a genetically predisposed individual develops the trait, making the etiology multifactorial [1]. As in the case of the torus, many theories describe the etiology of exostoses. It has been suggested that the bone outgrowth is due to increased or abnormal occlusal stress to the teeth in the areas involved [7]. As oral and palatine exostoses and TM are similar in morphology, it is suggested that the genetic threshold model can also be applied to oral and palatal exostosis [1].

Exostoses are self-limiting bone masses and hard on palpation. With normal staining, the coating mucosa appears stretched and intact. However, due to trauma or injury, ulcerations can be seen on the mucosa [8]. The frequency of exostoses increases with age, with a higher prevalence in adults who are aged 60 years or more $[2,8]$. With respect to sex, they are more common in men than in women $[2,9]$. They also show ethnic influences, with a higher prevalence among OceanicAsians (Mongoloid), Europeans (Caucasoid) [10], Eskimos [11] and Caucasian populations, while it is less prevalent in Africans [10].

Periapical and panoramic radiography are imaging methods used routinely for the initial examination of exostoses because they are simple, use a low dose of radiation, cost-effective, and allow the observation of various structures. However, these tests have limitations in the diagnosis of some pathologies due to their twodimensional representation. With the advancement in technology, the use of cone beam computed tomography (CBCT) allowed the evaluation of anatomical structures and diseases with greater precision, besides being easy to interpret and having higher image resolution. Furthermore, CBCT should be considered as an important diagnostic tool in dental practice [12].

If an excessive amount of bone is present, exostoses may present certain radiopacities in the dental radiographs. Thus, radiographically they appear as well defined circular or oval calcified structures, overlapping with the roots of the teeth. In cases where there is any doubt regarding the diagnosis, a biopsy is required [13].

In the present report, an unusual case of bilateral exostosis in the maxillary posterior region is presented, discussing the clinical aspects that make it uncommon and performing a tomographic analysis of the lesion, a resource that is rarely used in the evaluation of this abnormality. 


\section{CASE REPORT}

MCGB, a 68-year-old female patient, was referred to the Clinic of Pathology, Stomatology and Radiology of the Faculty of Dentistry at the Federal University of Minas Gerais for evaluation of bilateral swelling in the molar region and maxillary tuberosity. The patient had noticed a slow but constant increase of the masses in the previous 2 years, with no history of any type of symptom associated with this region, without discomfort or pain. The patient had a medical history of hypertension, for which she used medication regularly. The patient signed an informed consent form authorizing the publication and reproduction of the case.

The clinical examination of the oral cavity revealed a large increase in bilateral volume in the region of the molars and maxillary tuberosity (figure 1). Nodular lesions were observed, which were hard upon palpation and sessile. The overlying mucosa was smooth, thin and its coloration was similar to the oral mucosa.

Periapical radiographs and a panoramic radiograph were obtained to evaluate the alterations. Discrete radiopaque areas were observed in the panoramic radiograph (figure 2 ), with indefinite limits in the region of maxillary molars. In the periapical radiographs (figure 3), radiopaque, homogeneous images with well-defined oval borders were observed, interspersed with the trabecular bone in the posterior region of the maxilla bilaterally.

For a more detailed assessment and confirmation of the diagnosis, a CBCT was performed (figure 4). In the axial, coronal, and sagittal planes, it was observed that the bone margins were increased in the posterior region of the maxilla on the right and left sides and also bone projections with curvilinear contours. The cortical bone was very thick at the maxilla, mainly by the palatine and the bone trabeculate was within the normality pattern on both sides, with few increased medullary spaces in the region of the lesion on the right side. Considering the dimensions, the right side nodule was $1.96 \mathrm{~cm} \times 2.43 \mathrm{~cm}$ and the left side nodule was $2.6 \mathrm{~cm} \times 2.42 \mathrm{~cm}$ at its largest diameter, measured in the axial plane. These characteristics confirmed the diagnosis of exostosis and the patient is being monitored for the same.



Figure 1. Intraoral images. a) Frontal view of the oral cavity. b) Occlusal view of the maxilla. c) Occlusal view of the right side of the maxilla. d) Occlusal view of the left side of the maxilla. 


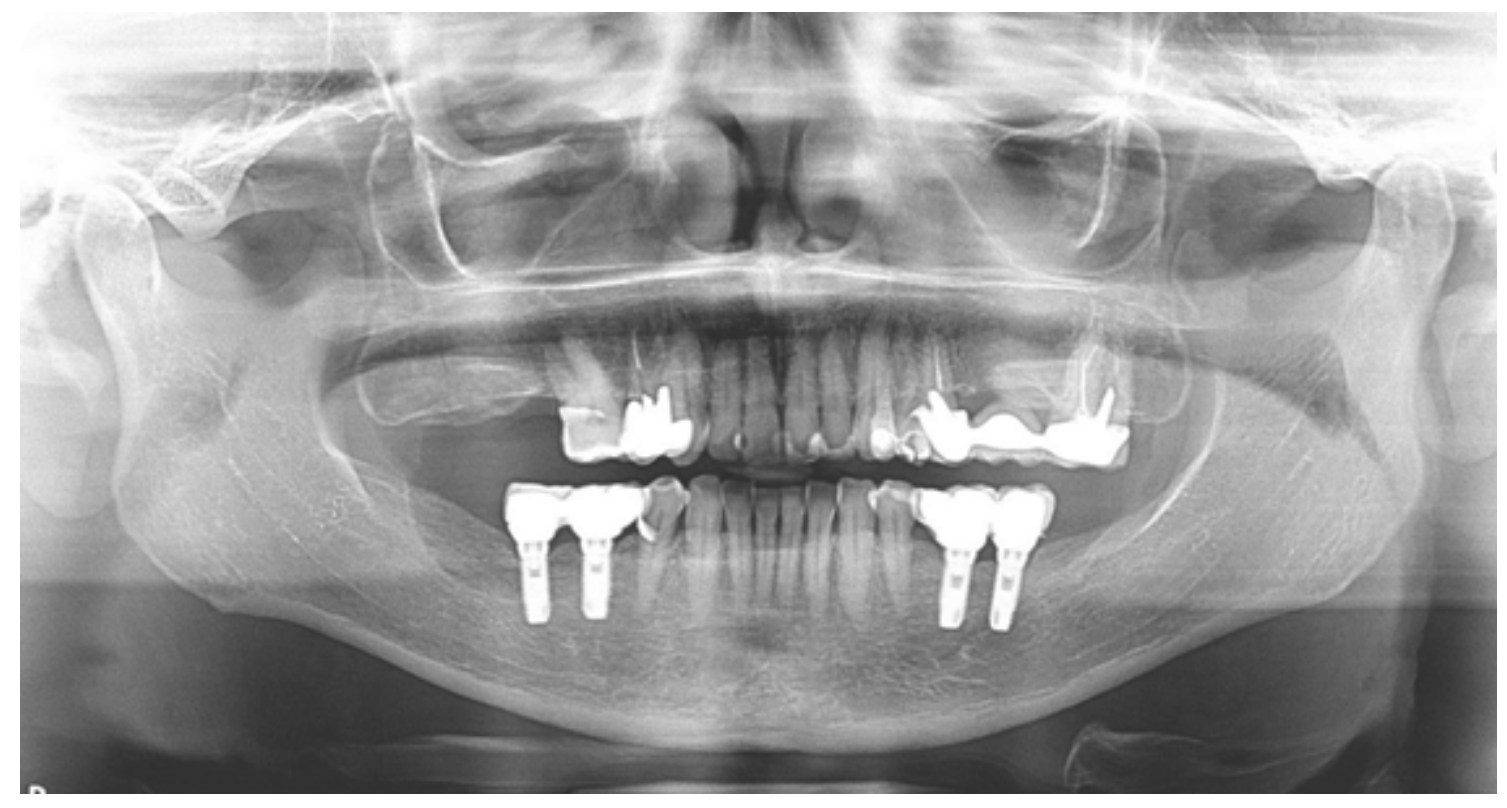

Figure 2. Panoramic radiography.

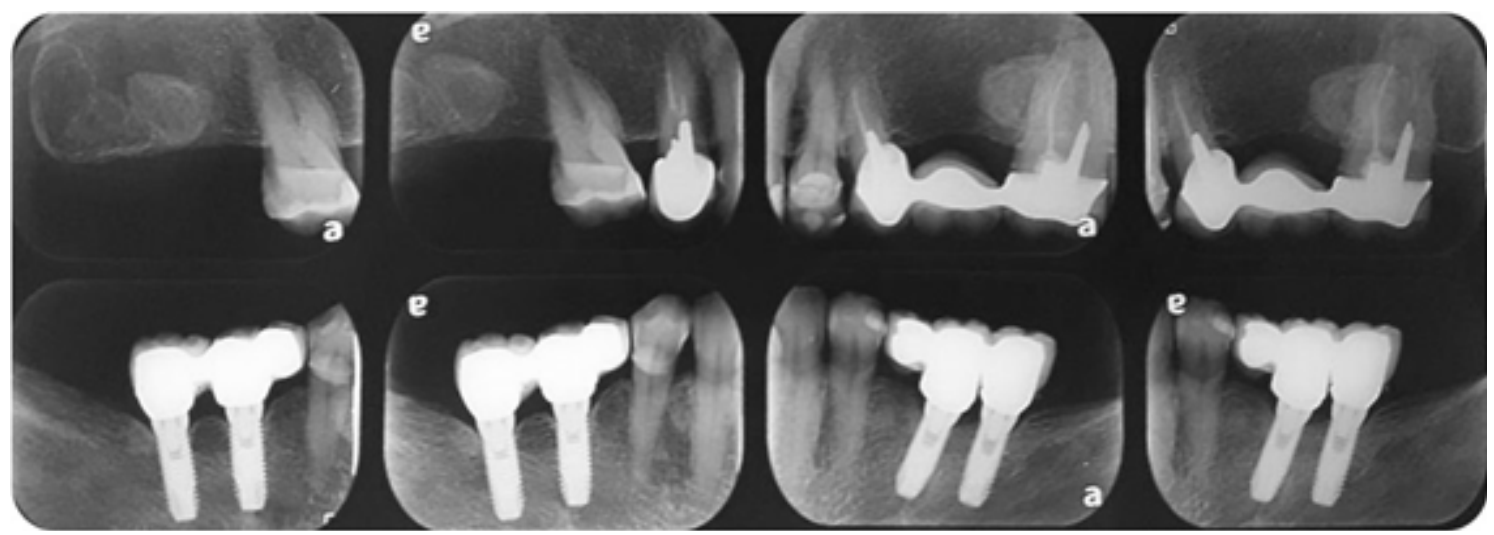

Figure 3. Periapical radiographs.



Figure 4. Cone beam computed tomography. a) Coronal plane. b) Sagittal plane. C) Axial plane. 


\section{DISCUSSION}

Exostoses can be described as localized nonpathological bone protuberances which arise from the cortical bone and sometimes from the spongy layer [1]. In general, the best explanation for the etiology of both types of torus and exostoses is the interaction between genetic factors (familial origin) $[5,6,11]$ and environmental factors including functional (masticatory hyperfunction), nutritional, and behavioral factors $[5,7]$. It was not possible to distinguish the origin of the exostosis in this case report since the lesion was present in the maxilla, where the right side appeared edentulous and the left side partially edentulous, which could exclude the functional etiology of one side, but not the other. Furthermore, the patient was not able to confirm if there was a similar case in the family, impeding an association of genetic inheritance. However, the patient may not have noticed the lesion before the extractions. Thus, the association of the exostosis with any of the etiologies described was not possible.

Although exostoses are significantly more frequent in men than in women (ratio 1.66:1) $[2,7,9]$ and torus palatinus is found predominantly in women (ratio $2: 1$ ) $[5,6,14]$, there is no obvious explanation for these differences, but a role of genetic factors have been suggested $[2,6]$. Although exostoses are more prevalent among men, this report illustrates a case of development of large exostoses in a female patient.

The occurrence of exostoses appear to be stable during adulthood (30-59 years), increasing slightly in older individuals (age $>60$ years) [2,3], which is in agreement with the findings of this study, since the patient was 68 years old and reported a perception and increase of lesions only 2 years previously. However, some authors $[9,10]$ suggest that the higher incidence of exostoses occurs between 40 and 50 years of age and decreases afterward. It is believed that exostoses arise in young individuals in undetectable sizes, which grows as the individual reaches adulthood when he/she is more predisposed to occlusal stress. As the individual grows older, the incidence of exostoses decreases due to edentulism $[9,10]$, which contradicts our findings since even with edentulism in the posterior region of the maxilla, exostoses developed in the patient.

Exostoses can be classified into small or large nodules; small nodules are usually multiple while large ones are single and rare and may involve large areas [3]. The most prevalent types are small and multiple nodules $[3,10]$. Usually exostoses are bilateral and quite symmetrical [9] and the most common site of occurrence is the alveolar process of the third upper molar, usually extending from the palatine surface of the maxillary tuberosity to the mesio-palatine aspect of the first molar [3,9]. These lesions have a gradual capacity of grow which may increase slowly, contributing to the development of periodontal diseases due to food retention and hygiene difficulties $[13,15]$. The clinical findings in this study regarding the location of the swellings were consistent with the literature, while in relation to size, large, bilateral and symmetrical lesions were observed.

Most of the exostoses are clinically diagnosed along with conventional radiographic interpretations, such as periapical and panoramic radiographs and generally do not require a biopsy $[15,16]$. Although scarcely used in these cases, CBCT is an important tool, because it allows differential diagnosis of exostoses from other conditions that may mimic them, without requiring invasive interventions. CBCT provides a three-dimensional view and multiplanar images, showing more details without overlapping structures, magnification, and image distortion while capable of demonstrating the bone composition (medullary and cortical). In addition, it allows the evaluation of the correlation of these anatomical variations with the adjacent structures, making it essential for the planning of the clinical approach $[12,17]$. Thus, in this study, we opted for computed tomography for the confirmation of the diagnosis, since the radiographic findings observed in panoramic and periapical radiographs were not specific to exostosis, raising the possibility of other bone disorders such as fibrous bone dysplasia, idiopathic osteosclerosis, and osteoma.

It is important to distinguish exostoses from initial stages of osteosarcomas and chondrosarcomas [15] and for patients with multiple bone outgrowths, one should evaluate the possibility of Gardner Syndrome $[15,16]$. Importantly, it should be distinguished mainly from osteomas, an unusual condition that produces similar clinical, radiographic, and histological features. Osteomas are benign neoplasms, which induce the proliferation of dense, compact cortical or medullary bone, usually located endosteally or periosteally [16]. Given the clinical similarity of osteomas with exostoses, it is important to note that osteoma, being a benign neoplasm, tends to grow continuously. Such a biological behavior differs from that presented by exostosis, which, as a developmental anomaly, 
grows during a certain period and then becomes inactive [18]. However, if the diagnosis is uncertain, a biopsy can be performed for the differential diagnosis of the bone lesions $[15,16]$. In the present report, the tomographic findings together with the history and the clinical aspects confirmed the diagnosis of exostosis, thus, the biopsy was not necessary.

The treatment of exostoses is usually unnecessary, unless it is affecting the periodontal conditions [8], causing functional changes in speech or chewing, becoming painful and ulcerated (due to constant trauma); there is a need for fitting of dental prosthesis [8,9], (due to the patient's aesthetic need), to allow appropriate adaptation of a mucoperiosteal flap during surgery, or to be used as a donor source for bone grafts $[9,16]$. Although with edentulism in the area, the patient reported that she was not planning for prosthesis placement. She did not present any complaints on changes in speech and chewing functions or on aesthetics; so, we opted for periodical observation of the case. The patient should be monitored periodically for possible clinical changes, such as the development of the lesion and/or radiographic changes, which may suggest a different diagnosis, or if any of the aforementioned situations occur indicating surgical removal.

\section{CONCLUSION}

The case reported illustrates a manifestation of large exostoses in the posterior region of the maxilla, bilaterally. Exostoses should not be ignored, since other bone conditions such as osteomas are clinically similar, and therefore, need to be carefully evaluated for confirmation of the diagnosis. Generally, the clinical evaluation and conventional examinations such as panoramic and periapical radiographs are enough for the diagnosis of exostoses, however, additional tests such as Cone Beam Computed Tomography provide a three-dimensional view, allowing the visualization of more details which are essential for the confirmation of the final diagnosis. Case reports are therefore important, especially for the clinical dentist who is not familiar with this entity, in order to avoid more invasive procedures.

\section{Collaborators}

ALL COSTA and ALM BATISTA were responsible for the research, revision and writing of the work. SFS COSTA carried out the clinical and photographic documentation of the case. JV BASTOS was responsible for the clinical examination of the patient, also contributing to the writing review. RMC MILAGRES and TMP AMARAL were responsible for guiding the work, for evaluating the images and also for the reviewing of the final writing.

\section{REFERENCES}

1. Auškalnis A, Bernhardt $O$, Putnienè $E$, Šidlauskas $A$, Andriuškevičiūtè I, Basevičienè N. Oral bony outgrowths: Prevalence and genetic factor influence. Study of twins. Medicina. 2015;51(4):228-232. https://doi.org/10.1016/j.medici. 2015.07.001

2. Jainkittivong A, Langlais RP. Buccal and palatal exostoses: prevalence and concurrence with tori. Oral Surg Oral Med Oral Pathol Oral Radiol Endod. 2000;90(1):48-53. https://doi. org/10.1067/moe.2000.105905

3. Larato DC. Palatal exostoses of the posterior maxillary alveolar process. J Periodontol. 1972;43(8):486-89. https://doi.org/10.19 02/jop. 1972.43.8.486

4. Reichart PA, Neuhaus F, Sookasem M. Prevalence of torus palatinus and torus mandibularis in Germans and Thais. Commun Dent Oral Epidemiol. 1988;16:61-4. https://doi. org/10.1111/j.1600-0528.1988.tb00557.x

5. Haugen LK. Palatine and mandibular tori. A morphologic study in the current Norwegian population. Acta Odontol Scand. 1992;50:65-77. https://doi.org/10.3109/000163592 09012748

6. Gorsky M, Raviv M, Kfir E, Moskona D. Prevalence of torus palatinus in a population of young and adult Israelis. Arch Oral Biol. 1996;41:623-5. https://doi.org/10.1016/0003-99 69(96)00149-5

7. Horning GM, Cohen ME, Neils TA. Buccal Alveolar Exostoses: Prevalence, Characteristics, and Evidence for Buttressing Bone Formation. J Periodontol. 2000;71(6):1032-42. https://doi. org/10.1902/jop.2000.71.6.1032

8. Medsinge SV, Kohad R, Budhiraja H, Singh A, Gurha S, Sharma A. Buccal exostosis: a rare entity. J Int Oral Health. 2015;7(5):62-64. https://www.ncbi.nlm.nih.gov/pmc/articles/ PMC4441241/

9. Sonnier KE, Horning GM, Cohen ME. Palatal Tubercles, Palatal Tori, and Mandibular Tori: Prevalence and Anatomical Features in a U.S. Population. J Periodontol. 1999;70(3):329-36. https:// doi.org/10.1902/jop.1999.70.3.329

10. Nery EB, Corn H,Eisenstein IL,. Palatal Exostosis in the Molar Region. J Periodontol. 1977;48(10):663-66. https://doi.org/10. 1902/jop. 1977.48.10.663

11. Smitha K, Smitha GP. Alveolar exostosis - revisited: A narrative review of the literature. J Dental Res. 2014;6(1):67-72. https:// doi.org/10.1016/j.sjdr.2014.02.001

12. Borie E, Watanabe PCA, Orsi IA, Fuentes R. Idiopathic bilateral antral exostoses: a rare case in maxillary sinus. Int J Surg Case Rep. 2014;5:624-627. doi: 10.1016/j.ijscr.2014.05.005 
13. Neville BW, Damm DD, Allen CM, Chi AC, editors. Oral and maxillofacial pathology. 4th ed. Philadelphia: W.B Saunders Co. 2016.

14. Eggen S, Natvig B, Gasemyr J. Variation in torus palatinus prevalence in Norway. Scand J Dent. Res. 1994:102:54-9. https://doi.org/10.1111/j.1600-0722.1994.tb01153.x

15. Siddiqui H, Singh DK, Mishra S, Mandal A. Bilateral buccal exostosis evaluated by cone-beam computed tomography: A rare accidental finding. Indian J Dent Sci. 2017;9:34-7. doi: 10.4103/IJDS.IJDS_95_16

16. Bouhoute M, Mezzour M, El Harti K, El Wady W. Bilateral maxillary buccal bone exostosis: rare case report. Acta Sci
Dental Sciences. 2017;1(7):2-5. https://actascientific.com/ ASDS/pdf/ASDS-01-0053.pdf

17. El Achkar VNR, Lopes SLPC, Pinto ASB, Prado RF, Kaminagakura E. Imaging aspects of palatal torus in cone beam computed tomography and magnetic resonance: case report. Acta Stomatol Croat. 2016;50(4):359-364. doi: 10.15644/asc50/4/10

18. Mafra RP, Vasconcelos RG, Queiroz LMG, Vasconcelos MG Maxillary osteoma: a case report. Rev Bras Ciênc Saúde. 2014;18(1):49-54. https://periodicos.ufpb.br/index.php/rbcs/ article/view/15250

Received on: 8/11/2018 Approved on: 7/6/2019 